\title{
HEAVY-OIL PRODUCTION USING EMULSION FLOODING
}

\author{
U. A. Usman ${ }^{1,}{ }^{*}$ and M. A. Jimme ${ }^{2}$ \\ 1 Department of GEOLOGy, University of MAIDUGURI, Maiduguri, Borno State, NiGERIA. \\ 2 DEPARTMENT OF GEOGRAPHY, UNIVERSITY OF MAIDUGURI, MAIDUGURI, BORNO STATE, NIGERIA. \\ E-mail addresses: ${ }^{1}$ attaayya@gmail.com, ${ }^{2}$ jimmeam@gmail.com
}

\begin{abstract}
In recovery of heavy crude oil by a sufficient means other than thermal recovery methods has been a great concern to researchers. Several researchers have found it difficult to achieve oil in-water $(O / W)$ emulsion stability status. In an effort to minimize the viscosity, heavy crude needs modification. The morphology and stability of oil-in-water emulsions were studied as a function of aqueous phase salinity. In reducing the viscosity of the heavy-oil, brine solutions were selected as alternative in forming oil-in-water $(O / W)$ emulsion. The aim of this research is to investigate the various salinity levels that influence viscosity and stability of oil-in-water emulsion. From observation, the loose emulsions were discovered through bottle test which showed complete separation on low salinity concentration. Optical microscope assembled with a digital camera was used to investigate the oil droplets of the stable and non-stable emulsion. Results indicated that phase separation appears more easily on low concentration at room temperature, and larger size droplets in the high concentrations. Therefore, using low salinity oil in water flooding, it reduces the viscosity of heavy crude oil.
\end{abstract}

Keywords: $A P I=$ American Petroleum Institute, EOR $=$ Enhanced Oil Recovery, GOR $=$ Gas Oil Ratio, OOIP $=$ Original Oil In Place, $O / W=$ Oil in Water, $W / O=$ Water in Oil.

\section{INTRODUCTION}

According to research the North of Alaska's pole has the deposit of the heavy crude almost twenty billion barrels in places called Ugunu, Shraeder Bluff reservoirs and West Sak. The United State of America heavy oil resources is around one hundred billion barrels of OOIP. The thermal methods for the oil recovery are very unattractive, because of their proximity to the permafrost. The heat from thermal method may melt this permafrost resulting in subsidence of the loose sand. These viscous oil reservoirs are much high in permeability and porosity, they are also unconsolidated and the order of $10,000 \mathrm{cp}$ is the viscosity of the oil, [3].

Secondary oil recovery method (water flooding) is an inexpensive and very common technique. Adverse mobility ratio between $10,000 \mathrm{cp}$ (oil) and $1 \mathrm{cp}$ (water) phase severely create the conduct of the water flooding for the viscous oils [1], [2]. Previous research has indicated that oil recovery can be improved by the application of water flooding. The water channel through the oil phase, and leaves most of the oil behind resulting too bad recoveries [3]. This research work concentrates on the emulsion method for heavy oil production, to reduce the viscosity of the heavy crude, brine concentrations can be injected into reservoir. This would generate oil in water emulsions with viscosities lower than that of the crude and hence help to reduce its viscosity. The objective of this dissertation is to study and identify potassium iodide (KI) concentrations than can make oil-in- water emulsions with heavy or light crude oil samples [4].

\section{SAMPLE PREPARATION AND EXPIREMENTAL TECHNIQUE}

\subsection{Preparation of aqueous phase}

Aqueous phase (brine) were prepared based on the concentrations of preparation of simple inorganic salt (KI) solutions stated by [5]. The potassium iodide (KI) salts for the whole samples were calculated and measured as equation 1 and the concentrations of the brine samples are displayed in the Table 1 .

$$
K I=\frac{M \times 166.003}{1000 \times M}
$$

In (1), $\mathrm{KI}$ is the potassium iodide, $\mathrm{M}$ is the mole concentration, 166.003 is the constant (molar mass of $\mathrm{KI})$. 
The salt and de-ionised water were mixed with magnetic stirrer which inserted into the beakers containing the brine and placed on the electric hot plate stirrer for active mixing and dissolution of dissolve potassium iodide (KI). The stirring of the salt is done for about $30-40$ minutes. The procedure is repeated for another 5 - 10 minutes, where total dissolution is not achieved, until total dissolution has been achieved.

Table 1: composition of the aqueous (brine) samples

\begin{tabular}{lllll}
\hline & Type A & Type B & Type C & Type D \\
\cline { 2 - 5 } Component & 1.00 & 0.05 moles & $\begin{array}{l}0.03 \\
\text { moles }\end{array}$ & 0.01 moles \\
& moles & & $1000 \mathrm{ml}$ & $1000 \mathrm{ml}$ \\
$\begin{array}{l}\text { De-ionised } \\
\text { water }\end{array}$ & $1000 \mathrm{ml}$ & $1000 \mathrm{ml}$ & $0.00498 \mathrm{~g}$ & $0.001660 \mathrm{~g}$ \\
$\begin{array}{l}\text { Potassium } \\
\text { iodide (KI) }\end{array}$ & $0.1660 \mathrm{~g}$ & $0.00830015 \mathrm{~g}$ & 0.00 \\
\hline
\end{tabular}

\subsection{Preparation of solid into the brine samples}

About $100 \mathrm{ml}$ of lowest brine sample was measured and transferred into other beakers. Solids powder were weighed using a beam balance and placed in a $100 \mathrm{ml}$ of brine and magnetic stirrer is inserted into the beakers containing the brine + solid samples and placed on hot plate stirrer for 45 minutes. The stirring is repeated again for another $10-15$ minutes, where complete dissolution of the solid is not achieved.

Table 2: Solid particles concentration into the brine sample (0.01mole)

\begin{tabular}{lllll}
\hline & Type A & Type B & Type C & Type D \\
\cline { 2 - 5 } Component & 1.00 & 0.05 & 0.03 & 0.01 \\
& moles & moles & moles & moles \\
Brine $(\mathrm{KI})$ & $100 \mathrm{ml}$ & $100 \mathrm{ml}$ & $100 \mathrm{ml}$ & $100 \mathrm{ml}$ \\
Solid & & & & \\
$\left(\mathrm{CaCO}_{3}\right)$ & - & - & - & $0.100 \mathrm{~g}$ \\
100.087 & & & & \\
\hline
\end{tabular}

The amount (g) of solid $\left(\mathrm{CaCO}_{3}\right)$ particles needed to prepare $100 \mathrm{ml}$ of various moles concentrations were calculate based on the formula below:

$$
\text { SOLID }=100 \mathrm{ml} \times\left(\frac{1 L}{1000 \mathrm{ml}}\right) \times \frac{M}{1 L} \times\left(\frac{100.087}{1 M}\right)
$$

Solid is the calcite powder $\left(\mathrm{CaCO}_{3}\right), 100 \mathrm{ml}$ is brine, $1 \mathrm{~L}$ is the constant value, $1000 \mathrm{ml}$ is the constant value, $\mathrm{M}$ is the mole concentration, 100.087 is the constant (molar mass of $\mathrm{CaCO}_{3}$ ),1 $1 \mathrm{M}$ is the constant value.

\subsection{Emulsion Preparation}

Crude oil sample was used in this research which has been obtained from Statoil, Norway, North Sea and blended with the fifty percent (50\%) n-dodecane, mixture of Isomers from Acros organic. In order analyse to meet the required amount of oil phase. In the pilot test, the water-in-oil and oil-in-water ratio was given at $3 / 1$, but more important oil-in-water emulsion stability was succeeded at $3 / 1$ ratio, with $74 \mathrm{ml}$ oil and $26 \mathrm{ml}$ brine. A simple hand homogenizer (OzeriDelux) at equivalent of 2500rpm.

\subsubsection{Assessments of emulsion stability}

The stability of emulsions is determined in the research by measuring the quantity of the water phase (typically dispersed phase) settled from the emulsions as an action of time, which is known as bottle test and the micro-emulsion analysis. After samples (emulsions) were prepared, the micro-emulsions were captured and recorded with GXM - 180M microscope, equipped with the GXCAM - 5 camera. The second phase of emulsion stability study in this research was recorded after an emulsion is formed, it has move and placed in Harrier 18/80 refrigerated (centrifuge). And the force from centrifugal which is $750 \mathrm{rpm}$ or acceleration is applied at choosing value at the temperature of the laboratory $\left(25^{\circ} \mathrm{C}\right)$. To examine the effect of temperature, on stability of the emulsion in the bottle test. The settled water amount is taken and recorded typically around $2 \mathrm{hrs}$.

\subsection{Viscosity Measurement.}

The viscosity of all the samples (crude oil, brine and emulsion) were determined with help of capillary viscometer. Materials used in the viscosity measurement; wash bottle, stop watch, capillary viscometer, puppets and weight balance machine. The viscosity values were calculated as follows:

$$
\eta_{2}=\left(\frac{\eta_{1} \times \rho_{2} \times t_{2}}{\rho_{1} \times t_{1}}\right)
$$

$\eta_{1}$ is the absolute viscosity of water, $t_{1}$ is the time of flow of water, $\rho_{1}$ is the Density of water, $\eta_{2}$ is the absolute viscosity of liquid, $t_{2}$ is the time of flow of liquid and $\rho_{2}$ is the density of liquid.

\section{RESULTS AND DISCUSSION}

\subsection{Centrifugation Analysis}

The emulsion stability is analysed based on the less percentage of water separated. In other hand, the greater stability of emulsion shows the smaller percentage of water separated from the oil-in-water emulsions.

The stability of emulsion in respect of centrifugation test were calculated using (4):

Emulsion stability $=100 \times \frac{1-\left(\mathrm{H}_{2} \mathrm{O} \text { separated }(\%)\right)}{\left(\mathrm{H}_{2} \mathrm{O} \text { content }(\%)\right)}(4)$ 

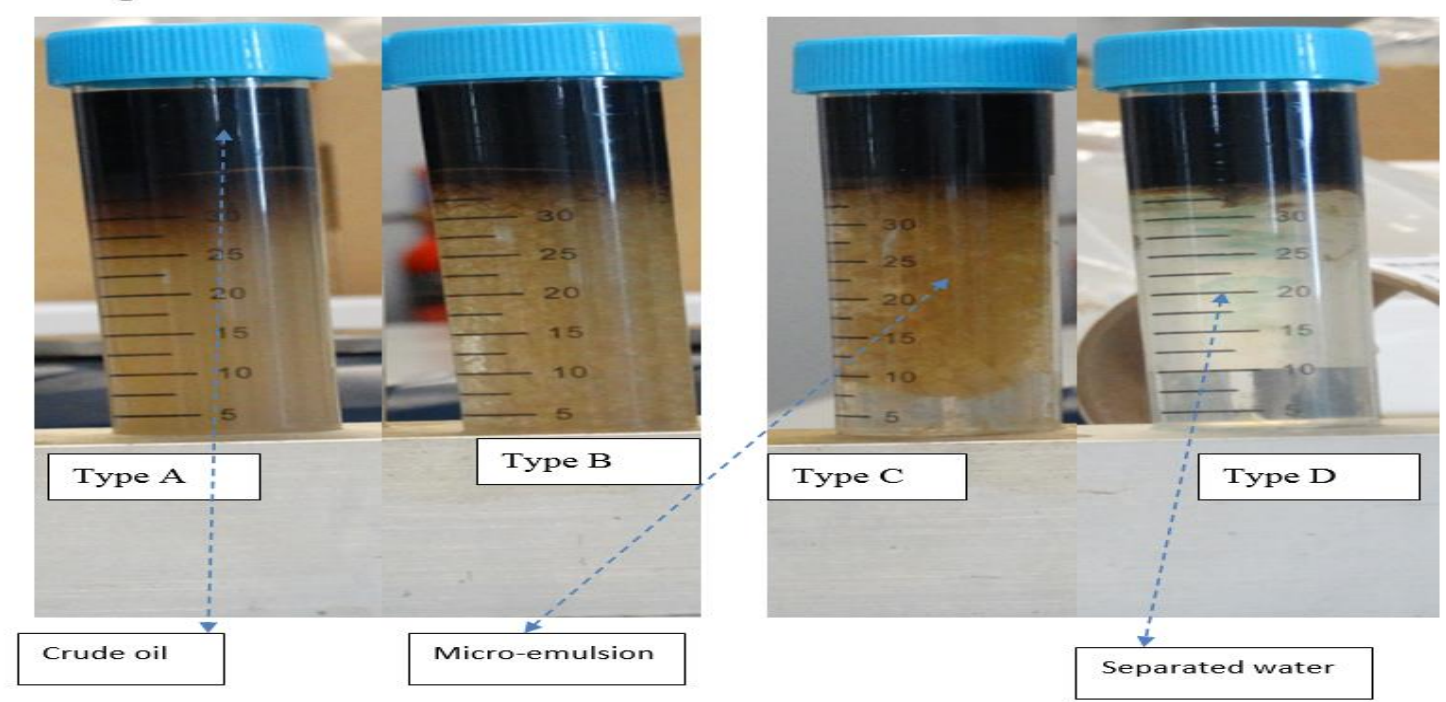

Fig 1: Centrifugation of oil-in-water emulsion samples. Time $2 \mathrm{hrs}$, Speed $750 \mathrm{rph}$, Temp $25^{\circ} \mathrm{C} .(A=1.0 \mathrm{~mol} / \mathrm{L}, B=0.05$ $\mathrm{mol} / \mathrm{L}, C=0.03 \mathrm{~mol} / \mathrm{L}$ and $D=0.01 \mathrm{~mol} / \mathrm{L})$.

At the end of centrifugation, each of the sample typically exhibits three (3) Phases as shown in Fig1.

The bottom phase of samples often appears as separated and it also free-standing water and its volume is measured and calculated:

Emulsion stability $($ Type A $)=100 * 1-(0.5 \mathrm{ml} / 37 \mathrm{ml})$ $=98.6 \%$

Emulsion stability $($ Type B $)=100 * 1-(2.5 \mathrm{ml} / 37 \mathrm{ml})$ $=93.2 \%$

Emulsion stability $($ Type C) $=100 * 1-(10 \mathrm{ml} / 37 \mathrm{ml})$ $=72.9 \%$

Emulsion stability (Type D) $=100 * 1$ $(36.5 \mathrm{ml} / 37 \mathrm{ml})=1.4 \%$

The emulsions types (a,b and c) are more stable than emulsion of type $\mathrm{D}$. The higher the concentration of brine it give stable emulsion and the lower concentration of aqueous phase less stability of the Oil/Water emulsion. According to the Fig 1, the type the emulsion has much amount of free-standing water and its measure as greater than $40 \%$ of the total volume of prepared oil-in-water emulsion, that indicate less stable emulsion. The middle portion of the centrifuged samples (Fig 1) appears brown in colour and consists of a tight oil-in-water emulsion when physically observed on the bottle samples as well as under optical microscope. The upper most part of the centrifuged samples looks black in colour which is crude oil concentration and with little amount of emulsions. We further the experimental work on the unstable emulsion (D). The brine concentration was kept constant as $0.01 \mathrm{~mol}$. $0.100 \mathrm{~g}$ of solid particle was added and transferred the emulsion to centrifuge machine for another $2 \mathrm{hrs}$. After centrifugation of unstable type D with additional solid particles, the sample exhibit stable emulsion (Fig 2). Below the crude oil portion of centrifuged sample shows lightbrown and with a tight oil-in-water emulsion.

The emulsion (Fig 2) stability factor $=100 * 1$ $(0.5 \mathrm{ml} / 37 \mathrm{ml})=98.6 \%$

The centrifugation result indicate and proved the solid particles with the influence of brine it improves the stability of the emulsion.

\subsection{Influence of Potassium iodide Concentration (KI) on Viscosity and Stability of Oil -in-Water Emulsion} The potassium iodide (KI) concentration promotes important aspect that influence the stability and viscosity of emulsions even without any surfactant, solids and other chemicals. As it can be noticed from Fig3 and Fig 4 the increasing of main potassium iodide (KI) concentrations in the aqueous phase will maximizes emulsion viscosity and emulsion stability, subsequently.

From the illustrations, the stability is expanded as potassium iodide (KI) concentration is increased from 0.01 to $1.0 \mathrm{~mol}$. We observed, where there is an increase of potassium iodide established in a maximizing in the volume of potassium iodide molecules adsorbed at the oil in-water interface, the interfacial tension falls with the increasing salt concentration, indicating positive adsorption of iodide. As a result of interfacial tension reduction, this can promote the emulsions of oil-in-water (Fig 5). Concurrently, the viscosity has importantly maximized when the concentration of potassium iodide increase. 


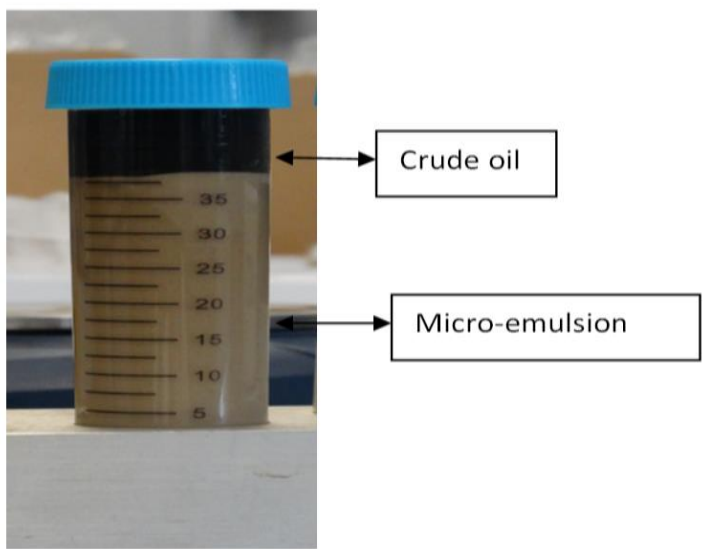

Fig2: Centrifugation of oil-in-water emulsion sample. Time 2hrs, Speed 750rpm and Temp 250C (0.01 mol + 0.100g solid).

We studied that the addition of potassium iodide concentration in the oil-in water emulsion will boost along the viscosity of the oil-in-water emulsion. The oil-in-water emulsion turn into more stable by adding the concentration of potassium iodide. The huge quantity of potassium iodide (KI) advocates each droplets from coalescence and the low the concentration of potassium iodide it reduced the amount of the oil droplets size and concentrations in the water (Fig 5). Therefore, we strongly believed the adding of potassium iodide concentration are effect and accessions of obstacle between the two phases (oil and water) and advocates excellent distribution of crude oil or any oil droplets (dispersed phase) in the continues phase (water).

\subsection{Emulsion Droplets}

The emulsion droplet size is significant variables which fickle which are affecting the rheological properties and colloidal stability such as deformation of emulsion and flow. The size of droplet circulation for the emulsion was resolved as an action of constant

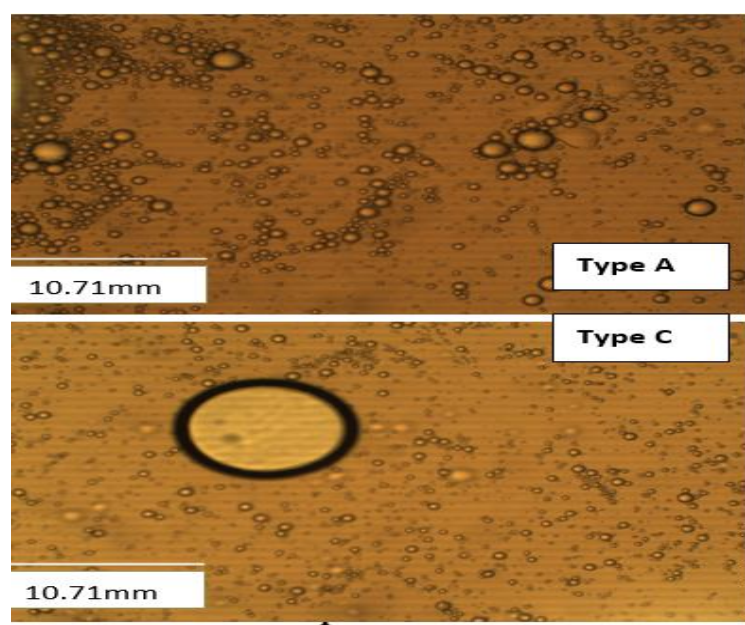

mixing speeds and potassium iodide (KI) concentration using GXM - 180M microscope, equipped with the GXCAM - 5 camera.

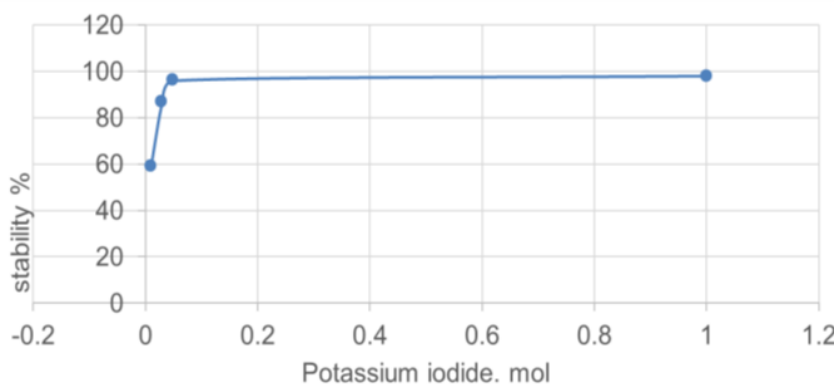

Fig 3: Effect of potassium iodide (KI) on O/W emulsion stability

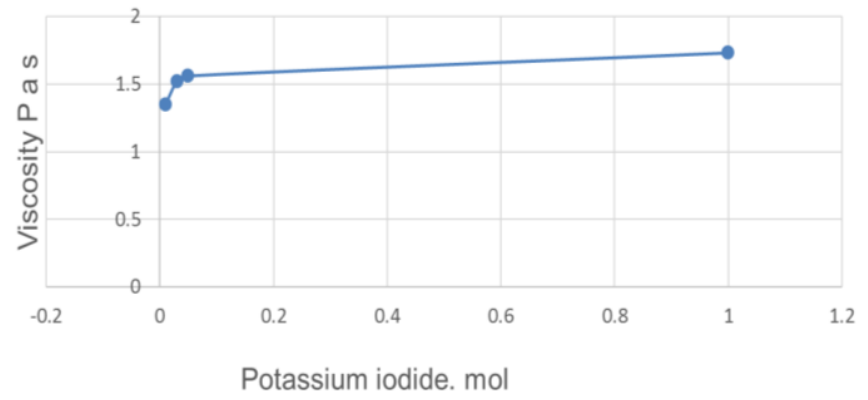

Fig 4: Effect of potassium iodide (KI) on O/W emulsion viscosity.

The droplets size measurement of optical micrograph of oil-in-water emulsions (Fig 6) were carried out based on the mathematical application as follows:

$$
\begin{gathered}
\text { size of the droplets }(\mathrm{mm})=\frac{\text { Scale of image }}{\text { Cell of Magnification }} \\
=\frac{\mathrm{X}}{\text { Length or Width (droplets) }}
\end{gathered}
$$

Fig 6 shows the higher mole concentration of potassium iodide brine samples are having larger droplets size of oil-in-water emulsions compare to those having low concentrations of potassium iodide brine or as the concentrations of salinity decreases, the droplets size are reducing.

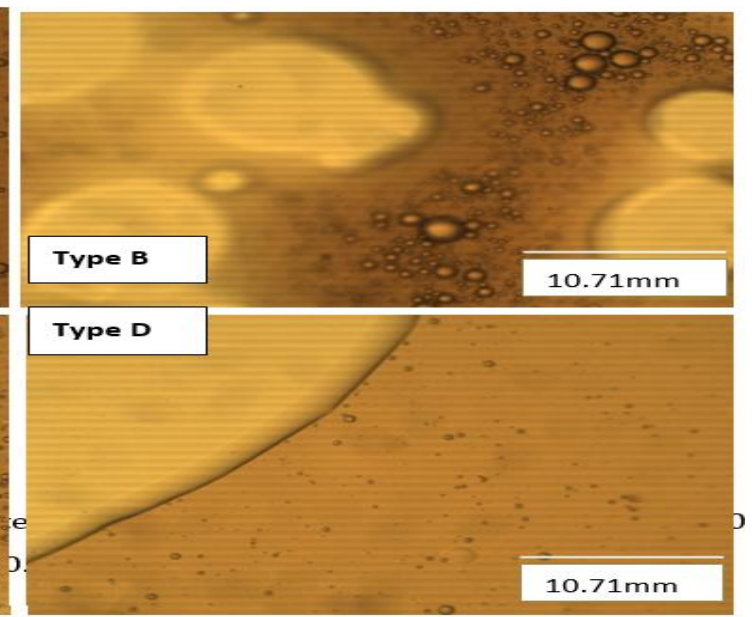

Fig. 5: Optical micrographs of oil-in-water emulsions without solid particles at 10/0.025 magnification $(A=1 \mathrm{~mol}, B=$ $0.05 \mathrm{~mol}, C=0.03 \mathrm{~mol}$ and $D=0.01 \mathrm{~mol}$ ). 


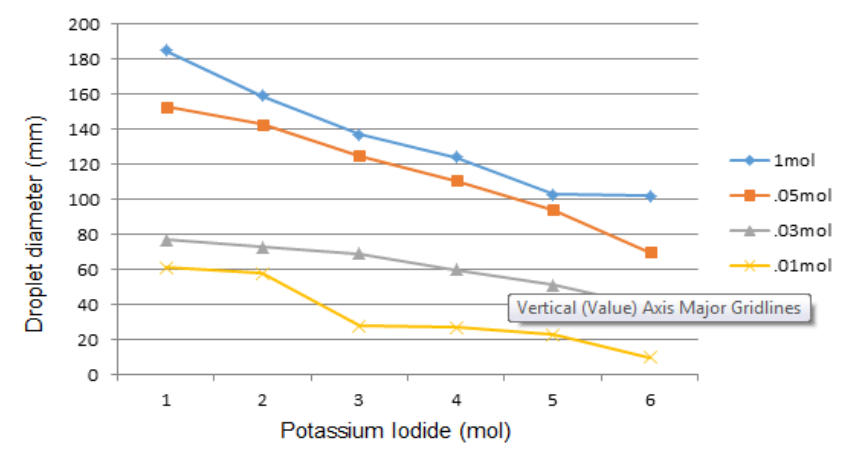

Fig 6: Effects of potassium iodide on emulsion droplets.

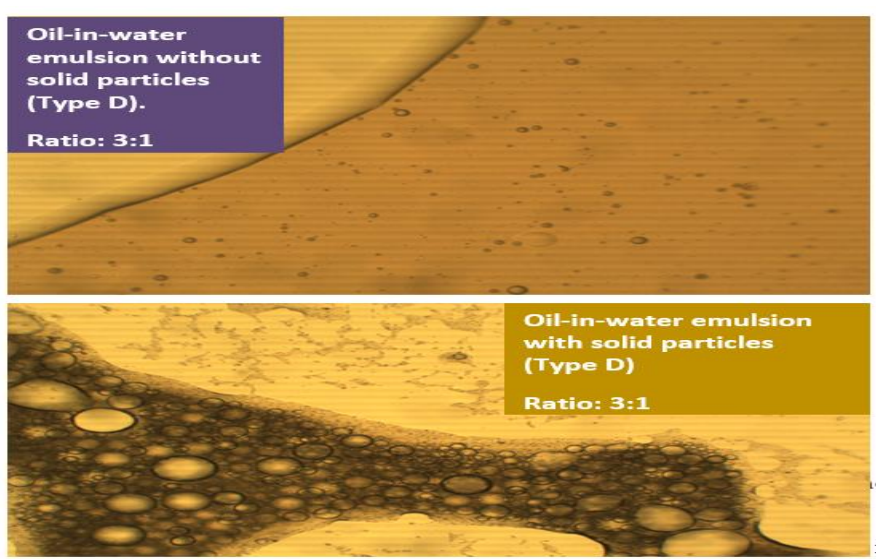

Fig 7: Optical micrographs of oil-in-water emulsions with and without solid particles.

The observed effects probably associated to the effect of potassium iodide (KI) on the aqueous solubility of emulsion parameters, or they probably associated to electrostatic interactions with compound of ions that available in the crude oil. These electrostatic interaction may be especially necessary for compounds having interfacial activity.

\subsection{Influence of Solid Particles on Oil-in-Water Emulsion Stability}

In lieu of this research, the emulsion of oil-in-water are stable only with higher concentration potassium iodide, we observe as the concentration of potassium iodide decreasing the stability of the emulsion as decreasing (Type A - Type D). The oil-in-water emulsion (type D) it shows the characteristics of low emulsion stability and even the centrifugation of the samples (Fig 1) the emulsion type D with $0.01 \mathrm{~mol}$ concentration of potassium iodide has the maximum separated water values. With the addition of calcium carbonate (CaCO3) particles it improve the recovery distribution and size of oil droplets compare to the emulsion samples with brine concentration only. Optical micrograph of oil-in-water emulsion of type D show the strong interfacial tension between the crude oil and the water phase due to the less of distribution and small size of oil droplets. However, when the solids were dangling in the water phase prior to emulsification, and 3:1 emulsion was prepared and studied under microscopic view. The oil-in-water emulsion stability was significantly increased (Fig7). The emulsion stability increased continuously with increasing volume portion of the disperse phase, in line with maximizing drop size. According to Fig7, the distribution of droplet size of stable emulsions explained that the sum interfacial field directly determined by the percentage of calcium carbonate particle added.

\section{CONCLUSION}

The conclusions compiled from this research study are as follows: The results of this work, shows the oil-inwater emulsions are characterized as Medium to lose oil-in-water emulsions. The emulsion stability experiments were studied phase separation test at $25^{\circ} \mathrm{C}$ was demonstrated: high separated brine from low concentration $(0.01 \mathrm{~mol})$ emulsion. The oil-inwater droplets size were reducing as brine concentration is reducing. The solid particles enhance the emulsions stability for the low brine concentrations. Viscosity of emulsions increases with increase in brine concentration. Low salinity water flooding can improve the heavy oil production.

\section{REFERRENCES}

[1] Abass, E., and Fahmi, A. 'Experimental Investigation of Low Salinity Hot Water Injection to Enhance the Recovery of Heavy Oil Reservoirs', North Africa Technical Conference and Exhibition, 15-17 April, Cairo, Egypt, 2013.

[2] Aichele, C. P., Chapman, W. G., Rhyne, L. D. and Subramani, H.J. 'Characterization of water-in-crude-oil emulsions in a complex shear field', Experimental Thermal and Fluid Science, 53, 2013 pp. 190-196.

[3] Bryan, J. L., and Kantzas, A. 'Improved Recovery Potential in Mature Heavy Oil Fields by AlkaliSurfactant Flooding', International Thermal Operations and Heavy Oil Symposium, 20-23 October, Calgary, Alberta, Canada 2008.

[4] Hammershaimb, E. C., Kuuskraa, V. A. and Paque, M. 'Major Tar Sand and Heavy Oil Deposits of the United States', in Curtis, F. A. (ed.) Energy Developments: New Forms, Renewables, and Conservation. Pergamon, 1984, pp. 77-83.

[5] Flinn, S.I. 'Science catalog reference', 2011, Available at: http://www.flinnsci.com (Accessed: 12/03/2015). 